\title{
JEAN PIAGET: DA EPISTEMOLOGIA GENÉTICA E SUAS APLICAÇÕES PARA O ENSINO E APRENDIZADO DA DANÇA
}

\section{English title: JEAN PIAGET: OF GENETIC EPISTEMOLOGY AND ITS APPLICATIONS FOR THE TEACHING AND LEARNING OF DANCE}

\author{
doi>10.33726/akdpapers2447-7656v10a62020p99-114 \\ PELICANO, Henrique José Rosa ${ }^{1}$ \\ FRANCESCHINI, Caroline Valente ${ }^{2}$ \\ FOGLIA, Daniela Brígida da Silva ${ }^{3}$
}

RESUMO: O presente trabalho objetiva demonstrar o liame entre a teoria de Jean Piaget e o ensino/aprendizagem da Arte da Dança. Por meio de uma metodologia de revisão bibliográfica, buscou-se apresentar brevemente 0 contexto e conteúdo da chamada Epistemologia Genética. Como resultados parciais, foi possível corroborar a importância do profissional de Psicologia nas escolas, sujeito este responsável por conectar atividades como a dança ao aprendizado construtivista de Piaget. Justifica a realização de um estudo como este, a necessidade que as escolas demandam em ampliar o repertório sociocultural a partir de práticas intelectuais e motoras.

PALAVRAS-CHAVE: Jean Piaget, Epistemologia Genética, Dança, Construtivismo

\begin{abstract}
This paper aims to demonstrate the link between Jean Piaget's theory and the teaching / learning of the Art of Dance. Through a literature review methodology, we sought to briefly present the context and content of the socalled Genetic Epistemology. As partial results, it was possible to corroborate the importance of the Psychology professional in schools, subject responsible for connecting activities such as dance to Piaget's constructivist learning. It justifies carrying out a study like this, the need that schools demand to expand the sociocultural repertoire from intellectual and motor practices.
\end{abstract}

KEYWORDS: Jean Piaget, Genetic Epistemology, Dance, Constructivism

\footnotetext{
1 Bacharel em Direito / UNIRP (2019). Especializando em Direito Ambiental. Graduando em História. Bacharel em Ciências Biológicas pela UNESP, Universidade Estadual Paulista Júlio de Mesquita Filho, campus de São José do Rio Preto, IBILCE (2012). Sócio fundador da Sociedade de Advogados "Nardo \& Pelicano". Graduando em Psicologia/UNIRP. Pós-graduando em Terapia Cognitivo-Comportamental. Carateca do estilo Shotokan.

2 Bacharela em Direito/UNIRP; Graduanda em Psicologia/UNIRP; Dançarina Belly-Dance / Dança do Ventre.

${ }^{3}$ Técnica em Farmácia; Graduanda em Psicologia/UNIRP.
} 


\section{INTRODUÇÃO}

No ambiente motivacional das discussões aqui impostas, o presente trabalho verte para um debate acerca da obra e legado de um dos maiores expoentes da ciência do século XX: Jean William Fritz Piaget, ou apenas, Jean Piaget, como este suíço é mundialmente reconhecido.

Sua contribuição não se encerra tão somente em uma grande área dos saberes humanos, muito pelo contrário, seu intelecto sempre estivera substancialmente ativado na seara da interdisciplinaridade, especialmente entre as ciências da Biologia e da Psicologia. De mais a mais, Piaget também é fundador da Epistemologia Genética, teoria esta que se debruça em buscar a construção e perpetuação do conhecimento. Ressalte-se ainda, neste sentido, que, como biólogo, a sua preocupação de como o conhecimento se perpetua é bastante natural, vez tal premissa implica de forma direta no entendimento dos mecanismos da ciência da evolução em seus pormenores biológicos, físicos e químicos.

Tal sagácia e inteligência possibilitaram ao cientista suíço observar com opípara atenção e arguta minúcia os seres humanos, especialmente as crianças. Tal o fez que, com brilhantismo, seu empirismo ofertou ao mundo os seus melhores préstimos ao alavancar a educação, precipuamente como corolário de sua Teoria dos Estágios de Desenvolvimento, a qual, mais adiante, será explanada pelo presente texto.

Destarte, veja-se, ictu oculi, breve epítome biográfico de Jean Piaget, visando situar o leitor no espaço-tempo em que viera ao mundo célebre pesquisador. Considera-se importante tal narrativa, não somente pelo valor histórico e biográfico, mas para que se compreendam melhor os primórdios e o entorno daquele que criaria e fincaria o pendão da Epistemologia Genética no seio do mundo. 


\section{BIOGRAFIA RESUMIDA DE JEAN PIAGET}

Nascido em Neuchâtel ("Novo Castelo", em francês), Suíça, em 1896, Piaget teve como sua primeira Alma Mater intelectual a Universidade de Neuchâtel. Mais tarde, lecionaria por décadas na Universidade de Genebra. Desde muito cedo, Piaget tivera contato com a Filosofia, especialmente pelos estudos da obra do francês Henri Bergson. Outrossim, era conhecedor dos elementos formadores da religião Cristã, frequentando os institutos protestantes pertinentes. Sua incessante busca pelo conhecimento o levaria a estudar Biologia e Filosofia, em Neuchâtel e, munindo-se cada vez mais de informações e de robustez nos conteúdos de História Natural, Piaget decidira trilhar também as veredas da Psicologia.

Num primeiro contato com a Psicologia e com a Psicanálise (parte analítica da Psicologia), inclusive conhecendo naquele momento, Carl Gustav Jung, Piaget não se sentiu motivado a dar seguimento com a corrente psicanalítica. Ilação do narrado, preferira, então, engendrar-se numa Psicologia mais conectada com as Ciências Naturais, ciências mais consagradas e de corpus distinto do subjetivismo analítico que, em princípio, não o interessara.

No deslinde do exposto, Piaget colocou à prova sua vocação experimental no laboratório de Alfred Binet, onde semeou as radículas de sua metodologia. Ato contínuo fora convidado para integrar o Instituto JeanJacques Rousseau, na Universidade de Genebra (Gomes \& Bellini, 2009). Emília Ferreira (2001) declara: "Piaget aceita, sem imaginar que havia encontrado o lugar de trabalho que não haveria de abandonar jamais. $E$ notese que isto aconteceu ainda em 1921".

Ainda neste diapasão, embebido e plotado num terreno que the concedera oportunidades para o avanço de suas pesquisas, Piaget presenteou o mundo com obras de suma importância, sendo prolífico escritor, e.g., "O Raciocínio da Criança", "A Equilibração das Estruturas Cognitivas", "A Epistemologia Genética”, "A Construção do Real na Criança”, dentre outras.

Aos aplausos da comunidade científica, como excepcional cientista, escritor e pensador, Piaget, além de sua contribuição em âmbito estritamente acadêmico, no âmbito da ciência per se, isto é, na raiz da eficácia e no topo do 
efeito, impulsionou a Pedagogia, afrontando escolas mais tradicionalistas do passado, por meio da proposta de uma Escola Ativa (onde a criança primaria pela ação, em detrimento de ser ela objeto de manipulação). Propostas símiles, como a dos escolanovistas ${ }^{4}$, também beberam da fonte da Teoria Piagetiana.

Em 1980, em Genebra, o gênio suíço encerrou sua jornada na Terra, marcando com tinta permanente seu nome na História. Do valioso legado, não se prescindem alguns conceitos-chave para que o leitor melhor compreenda a Teoria de Jean Piaget.

Com fito explicativo das relações interdisciplinares apontadas no título de nosso trabalho, apresentaremos breves apontamentos sobre a arte da Dança e, na sequência, inauguram-se mais enfaticamente os conceitos de Equilibração, Acomodação, Assimilação e Adaptação, capazes de promover o enlace entre a epistemologia genética e a dança propriamente dita.

\section{BREVES COMENTÁRIOS SOBRE A DANÇA}

De maneira simplista, pode-se dizer que a dança é uma expressão do corpo, que se realiza por meio de movimentos. Estes movimentos, por sua vez, estruturam-se numa lógica rítmica apropriada a cada tipo ou estilo de dança. Ademais, não se deve olvidar a forte carga subjetiva atinente à prática, ou seja, a mensagem ou conteúdo que o indivíduo almeja expressar por intermédio de sua arte.

Desde já, não se fere qualquer preceito, inferir ser fortíssimo o liame entre a música e a dança. Trata-se de expressão conhecida como Arte milenar praticada por diferentes culturas e civilizações durante a História, cada qual com suas particularidades, ritmo, modo de expressão, sentimento, emoção e mensagem.

Atualmente não é diferente, a Arte, em especial a dança, toca o homem de diversas maneiras. Menos observado é o quanto dançar trabalha em prol do

\footnotetext{
${ }^{4}$ Embora presente no Brasil, desde 1882, por meio do pensamento de Rui Barbosa (1849-1923), o escolanovismo brasileiro ganhou maior fôlego, a partir de 1932, com o "Manifesto dos Pioneiros da Educação Nova". Por aqui, ainda que mais afeitos ao pensamento de John Dewey, a Escola Nova tupiniquim adotava por princípios a ideia de que a escola não poderia se preocupar em preparar o aprendiz para a vida, mas sim, que deveria ser a sua própria vida. Desse modo, a educação nova teria como eixo norteador a vida-experiência e a aprendizagem, elementos os quais se aproximariam do postulado piagetiano de uma aprendizagem proativa.
} 
desenvolvimento sociocultural e psicognitivo humano. Por isso, além de ser forte componente educativo, ela favorece o desenvolvimento infantil em seus aspectos sociais, cognitivos, motores, acadêmicos e afetivos, emocionais (SILVA et al., 2020).

Observa-se que o brincar é atividade essencial para o desenvolvimento em todas as suas esferas, tal como explica Piaget. Estimula a criatividade, explora os limites corporais, cognitivos e emocionais, sendo, assim, um dos primeiros modos da criança conhecer seu corpo e seus movimentos.

A dança, por sua vez, possui significado parecido, isto é, ela possibilita a criatividade, a consciência corporal, ajuda nos processos de memorização, coordenação motora, noção de tempo e espaço, da mesma maneira que estimula a autonomia (processo importante explorado por Piaget, a ser alcançado durante as fases de desenvolvimento).

Platão, filósofo grego, utilizava da dança justamente para esse fim, ou seja, educar discípulos, o que corrobora mais uma vez, a ação da dança e suas potencialidades em relação à percepção, a imaginação, a sensação e a influência acerca do processo intelectual e de aprendizagem (SILVA et al., 2020).

Além dos processos acima mencionados, a dança trabalha a formação ética, atitudes de decisão, moralidade, pensamento plural, hipóteses e deduções lógico-causais, fenômenos estes explicados e defendidos pelo estágio Operatório-Concreto da Teoria Piagetiana.

Portanto, o indivíduo que se ativa para o aprendizado da dança encontrará uma sequência de movimentos a ser apresentada de acordo com o progresso do estudante. Movimentos de cinemática e mecânica mais simples, obviamente são ensinados ao iniciante. Portanto, ao aprender determinado passo, o estudante estará assimilando o conceito e, assim, reunindo esquemas de ação, os quais irão ser impressionados pela chamada Acomodação.

Exemplifique-se, num tipo de prática em particular, na Dança do Ventre. Nesta variante da Arte, há um passo chamado "Shimmie", que consiste em movimentos rápidos, simétricos do quadril, em que a dançarina parece "tremer" o quadril/ventre de forma independente do resto do corpo. Há ainda outros passos derivados do "Shimmie", e.g. "Shimmie lateral", "Shimmie em 
deslocamento" etc. Contudo, para que a estudante de Dança do Ventre atinja esses passos mais derivados é necessário que se tenha aprendido o elemento principal do Shimmie. Veja-se então que, este exercício, é imprescindível que se assimile 0 passo original, compondo um esquema de ação e, posteriormente, por meio da Acomodação, sejam os demais passos incorporados.

\section{DOS CONCEITOS ELEMENTARES}

Para a concatenação lógica dos conceitos em tela, elenque-se como supedâneo o conceito de Equilibração.

Entende-se pelo conceito Equilibração, uma sucessão de níveis de equilíbrio, consoante bem explica Gomes \& Bellini (2009). Ocorre que tal sucessão não ocorrerá se não houver um real atingimento do nível a quo. Incorre-se assim, em Conditio Sine Qua Non, que a Equilibração ocorrerá. Consiste ainda em um mecanismo de autorregulação, compondo-se como ponto de equilíbrio entre outros dois conceitos ainda a serem discutidos: a Assimilação e a Acomodação (WADSWORTH, 1996).

Jean Piaget, em sua obra "A Equilibração das Estruturas Cognitivas" (1975), postulou os seguintes tópicos:

- Primeiro Postulado: Todo esquema de assimilação tende a alimentar-se, isto é, a incorporar elementos que lhe são exteriores e compatíveis com a sua natureza; e,

- Segundo Postulado: Todo esquema de assimilação é obrigado a se acomodar aos elementos que assimila, isto é, a se modificar em função de suas particularidades, mas, sem com isso, perder sua continuidade (portanto, seu fechamento enquanto ciclo de processos interdependentes), nem seus poderes anteriores de assimilação.

Posto isso, verifica-se a relação binária, indissociável, entre a Assimilação e Acomodação para a ocorrência da Equilibração. Em se tratando, contudo, da Assimilação e da Acomodação, vê-se que são invariantes funcionais que se configuram como conceitos essenciais para o entendimento da Teoria de Piaget. 
Primeiro, porque, como já dito, orquestram de forma entrelaçada a sucessão dos níveis de equilíbrio, ou seja, da Equilibração. Segundo, porque, além de fornecerem as diretrizes do aprendizado do indivíduo, estão relacionadas também à Adaptação.

A assimilação pode ser entendida, portanto, como a função de absorver ou integrar um novo objeto (elemento, experiência) aos esquemas psíquicos, sensoriais, biológicos e emocionais pré-existentes do indivíduo. Trata-se de uma incorporação aos esquemas prévios e, enfatize-se, não há modificação nos esquemas em tela.

Noutro giro, é justamente na chamada Acomodação que as modificações se realizam. Tal mecanismo fomenta uma transformação em decorrência do novo objeto e do ambiente em que se fez presente. Logo, infere-se sem qualquer soslaio de receio que, enquanto a assimilação é de foro externo, justamente por incorporar-se o objeto, a Acomodação é internalizada e, em virtude das alterações dos esquemas de ação, propicia-se o atingimento de novo patamar de equilíbrio. Por conseguinte, o enlace desses conceitos também serve de espeque para a Adaptação do indivíduo, qual seja, o que se passa a expor a seguir no tocante à Adaptação.

Nos termos do já acenados, como Piaget era biólogo de formação, espera-se sob a égide da normalidade que o conceito de Adaptação esteja atrelado à forma de pensar de um biólogo, dentro do orbe darwiniano e de seus símiles, conquanto seu escopo sempre fora o de entender a evolução e a perpetuação do conhecimento. Logo, resta de veras evidente, que o conceito de Adaptação é, senão outro, a ocorrência de uma alteração ou transformação do indivíduo para com o meio, desde que a mesma seja positivamente considerada.

É cediço, desde Dobzhansky, que a Evolução atua como força cega, não dispondo de predileções. No palco da vida, eventos como glaciações (em especial a Varangiana, que colocara o mundo em snowball), vulcanismos, isolamentos geográficos e genéticos, especiações, competições dentre tantos outros elementos, atuam na loteria da vida, onde os mais favorecidos são os mais aptos para tal espaço, situação e época. 
Assim, é absolutamente incorreto considerar que a espécie evoluiu se, e somente se, uma característica geno ou fenotípica tenha lhe trazido qualquer valia. À luz dos dizeres de então, aquele grupo que tenha sofrido uma alteração (qualquer que seja, e.g. cor da pele, tamanho da cauda etc.) e que tenha perecido em função da mesma, também evoluiu. Logo, o que seria, então, das sinapomorfias do ponto de vista da cladística?

Piaget, contudo, conhecedor da teoria, as analisou e pressupôs exatamente que o conceito de Adaptação bem o serviria, porquanto ela demanda que tenha havido uma positividade indivíduo-meio, por óbvio. Assim, o conceito biológico, com as ressalvas de estilo, serviria perfeitamente para professar o que seria a Adaptação na Teoria Piagetiana.

Ultima Ratio da Equilibração, vistos restam os conceitos mais elementares para a compreensão da Epistemologia Genética. Siga-se, pois, com a leitura dos Estágios de Desenvolvimento de Piaget, consoante sua obra "Seis Estudos de Psicologia" (2017).

\section{DOS ESTÁGIOS DE DESENVOLVIMENTO COGNITIVO}

Inicialmente, é válido mencionar que alguns estudiosos discordam do vocábulo "estágio", preferindo, pois, "estádio". Neste sentido, explana Fernando Becker, em curso ministrado na Universidade Federal do Rio Grande Sul, que a melhor tradução para o português deveria ser "estádio", posto que assim, com a clava assertiva da sensibilidade da melhor tradução, a ideia original de plateaux, Stadivm, conservar-se-ia no idioma pátrio. Com reservas de convenção, as etapas intermediárias entre um e outro ponto, serão, aqui, tratadas por "estágios".

Filologias e metaplasmos à parte, natural é que se expliquem quais seriam os quatro estágios de Jean Piaget, a saber: (I) Sensório-Motor, (II) PréOperatório, (III) Operatório-Concreto e (IV) Operatório-Formal. Fundamental salientar que tais estágios cognitivos são classificados em torno de uma estimativa de idade. Em nada fere a teoria aquele indivíduo que venha a destoar da idade média dos períodos previstos para cada estágio. Soma-se 
ainda que o atingimento dos níveis segue uma ordem convencional, sem prejuízo das exceções que sobrevierem.

\section{V.1 Sensório-Motor (0-2 anos)}

Trata-se este Estágio, da fase em que o bebê começará a desenvolver sua percepção e habilidades motoras (motricidade). A descoberta das sensações e de si próprio estão em função dos estímulos que mais lhe impressionarem, num constructo que parte do intrínseco com diretivas extrínsecas.

Tais construções se exemplificam quando o bebê passa a acompanhar determinado objeto com os olhos e busca encontrá-lo, ainda quando o mesmo desapareça de seu campo visual. Fase de reflexos como o de sucção, o bebê, adquire paulatinamente habilidades como engatinhar e manipular objetos. Com o avanço do estágio, o indivíduo se ativa a se entender como parte do todo, ou seja, um elemento a mais no mundo e no espaço.

\section{V.2 Pré-Operatório (2-7 anos)}

Momento em que se destaca o desenvolvimento da linguagem e, corolário, de todo o conjunto de habilidades e conquistas que tal aprendizado oferta: expressar seus anseios e medos, o início do entendimento e incorporação dos símbolos, curiosidade exacerbada, vez que almeja saber o "porquê" das coisas e alta capacidade imaginativa são características de tal fase.

O animismo é conspícuo, haja vista que todos os objetos são animados (Piaget exemplifica com a Lua) e a criança, por não ter domínio pleno da linguagem, comumente dispõe do mimetismo para se expressar.

Ao seu turno, conceitos matemáticos e demais abstrações não são bem compreendidos. Grandezas como volume, quantidade, massa também não raro confundem os indivíduos nesse estágio.

Ademais, desenvolve-se o senso de obediência (mais por temor) aos pais, às regras de convívio social e, assim, move-se para o final do 
encerramento da fase, momento em que se dá início à uma maior preocupação com o outro do que apenas consigo.

\section{V.3 Operatório-Concreto (7-11 anos)}

Há um importante avanço na cognição do indivíduo no campo da abstração e conhecimento matemático. Conceitos como quantidade, séries numéricas, volume e área passam a ser estudados e compreendidos. Com o avanço do desprendimento dos pais, o indivíduo torna-se mais autônomo e, assim, começa a desenvolver sua própria moral e opinião.

É também nesta fase que se alicerçam os conceitos de justiça, de pensamento plural, hipóteses e deduções lógico-causais, temporalidade, cronologia, ambivalências entre direitos e deveres, vontades e imperativos, investiduras no social,

\section{V.4 Operatório-Formal (Acima de 11 anos)}

Avança-se com o desenvolvimento cognitivo, agora já com capacidade de conjecturar abstrações lógico-matemáticas de formas disjuntas a qualquer estrutura concreta, lançar teorias, postulados, hipóteses, análises, conclusões e discussões. Prima pela realidade, sabendo ponderar o que pensa e o que é real. Calcula e mensura maneiras de se enquadrar e agir no mundo, de forma que se inaugura uma fase delicada no quesito de preferências e referências.

A família perde espaço para as amizades no quesito referencial, ao ritmo em que a volatilidade das vontades impera: comumente o indivíduo queria ser médico ontem, piloto hoje e fazendeiro amanhã. Testa diferentes cursos, experiências etc. Sua moral se alicerça e recebe bem menos influências. Da profusão de confrontos de foro íntimo, é uma fase de maior isolamento social. A resolução disto somente far-se-á com a maturidade da fase adulta.

Assim, vistos os conceitos mais elementares, máxime por sua importância na compreensão da teoria, o próximo tópico a ser ventilado versará sobre como a Filosofia influenciou a obra de Jean Piaget e de como tal arcabouço teórico se perfaz na atuação do Psicólogo. 


\section{CONTEXTO CIENTÍFICO DA EPISTEMOLOGIA GENÉTICA}

Com intento de estudar a conquista e manutenção do conhecimento, cunhando a chamada Epistemologia Genética, o biólogo suíço uniu fatores empíricos verificáveis (respaldando-se nas ciências biológicas) e questionamentos de cunho essencialmente filosóficos, posto que, desde seus primeiros trabalhos em Genebra, sempre se atentara para além das estatísticas, interessando-se nas razões que levavam ao dado estatístico.

Não é de se surpreender que lecionasse a disciplina de "Filosofia da Ciência" e tenha trilhado entre os binômios de caracteres quantitativos $\boldsymbol{x}$ qualitativos, razão $\boldsymbol{x}$ empirismo, sujeito $\boldsymbol{x}$ objeto; versado em filosofia e ciência, com especial atenção aos estudos da obra darwiniana.

Com universo amostral na espécie humana, tomando por subconjunto as crianças, Piaget enunciou e estruturou sua teoria de forma a explicar o conhecimento de maneira construtivista, com a relação biunívoca entre sujeito e objeto, respeitando-se cada patamar de equilíbrio e seus esquemas de ação atinentes, bem como os estágios de desenvolvimento cognitivo, desde que nos moldes do que batizara de Equilibração.

Ao esmiuçar com olhos de águia o desenvolvimento do ser humano, paralelamente traçava $o$ processo de aprendizagem e perpetuação do conhecimento. Sua hermenêutica não é a única e existem outros pesquisadores de mesmo jaez, é bem verdade.

Piaget, no entanto, teve sua teoria aceita e reconhecida internacionalmente, sendo de importância magnânima para a Pedagogia, Psicopedagogia e ciências afins. Escolas aqui e alhures empregam a Teoria Piagetiana e, neste átimo, elenque-se com justiça a figura do profissional de Psicologia.

Para fins de ciência, conforme cita Terra (2005), em seu Artigo "O Desenvolvimento Humano na Teoria de Piaget" e no Artigo de autoria de Araújo et al.(2020), "As Contribuições da Psicologia Cognitiva e a Atuação do Psicólogo no Contexto Escolar", algumas complicações e até mesmo confusões em relação à Teoria propriamente dita e a forma pela qual é aplicada. 
Neste sentido, Terra (2005):

[...] a aplicação educacional da teoria genética tem como fatores complicadores, entre outros: a) as dificuldades de ordem técnica, metodológicas e teóricas no uso de provas operatórias como instrumento de diagnóstico psicopedagógico, exigindo um alto grau de especialização e de prudência profissional, a fim de se evitar os riscos de sérios erros; b) a predominância no "como" ensinar coloca o objetivo do "o quê" ensinar em segundo plano, contrapondo-se, dessa forma, ao caráter fundamental de transmissão do saber acumulado culturalmente que é uma função da instituição escolar, por ser esta de caráter preeminentemente político-metodológico e não técnico como tradicionalmente se procurou incutir nas ideias da sociedade; c) a parte social da escola fica prejudicada uma vez que o raciocínio por trás da argumentação de que a criança vai atingir o estágio operatório secundariza a noção do desenvolvimento do pensamento crítico; d) a ideia básica do construtivismo postulando que a atividade de organização e planificação da aquisição de conhecimentos estão à cargo do aluno acaba por não dar conta de explicar o caráter da intervenção por parte do professor; e) a ideia de que o indivíduo apropria os conteúdos em conformidade com o desenvolvimento das suas estruturas cognitivas estabelece o desafio da descoberta do "grau ótimo de desequilíbrio", ou seja, o objeto a conhecer não deve estar nem além nem aquém da capacidade do aprendiz conhecedor (p. 01).

Em contrapartida, a Teoria trouxe grande contribuição acerca de possíveis objetivos a serem trabalhados no âmbito educacional, uma vez que Piaget elenca detalhadamente aspectos inerentes ao desenvolvimento da criança, bem como, a questão dos diferentes estilos individuais de aprendizagem. Logo, vê-se que o psicólogo conhecedor da teoria em tela ofertara valioso serviço à Instituição e seus pacientes.

Sendo esta uma teoria que aborda metodologias de ensino e aprendizagem que respeitam cada individualidade, o psicólogo poderá ter sua atuação fortemente ativa, sugerindo, avaliando, informando, discutindo, observando e demais atividades de estilo, desde um único paciente até a cúpula diretiva dos projetos escolares.

Assegurado o melhor meio para o desenvolvimento das potencialidades do indivíduo e, nas escolas, vê-se que a figura do psicólogo vem se fortificando. Note-se que, cada vez mais, as escolas estão se preocupando em ofertar aos seus estudantes atividades complementares: artes marciais, música, dança, jogos coletivos etc. 
À vista disso, a aplicação da Teoria Piagetiana vem desbravando limites e, por estes mesmos trilhos, expôs-se de modo válido neste paper um liame entre a aprendizagem da arte da dança e a Teoria Piagetiana, uma vez que em ambos os territórios, há de se enxergar processos de ancoragem nas categorias piagetianas supramencionadas.

\section{ANÁLISE DOS DADOS}

Nota-se que Piaget demonstrara interesse e apreço pelos estudos filosóficos desde muito jovem. Não é qualquer indivíduo que liga os motores da curiosidade para ler Henri Bergson.

Além da primazia de seus interesses em História Natural, já se fora dito aqui que é muito importante entender o contexto em que determinada convicção fora desenvolvida.

Não é de hoje que os historiadores debatem sobre qual seria a melhor forma de se entender a História. A escola germânica, por exemplo, pautada em documentos formais, digladiava com a escola francesa (frise-se, tal antagonismo não é apenas em História, mas numa miríade de outras áreas).

Para tanto, não é preciso ir muito longe, basta que se traga à memória o Possibilismo Geográfico de La Blache, francês, contra o Determinismo Geográfico, do alemão Ratzel). Há ainda novas hermenêuticas, inclusive a de uma "História vista por baixo", onde personagens geralmente anônimos e sem destaque contam os eventos que presenciaram, como viveram etc.

Todavia, é praticamente uníssona a ideia de que o bom estudioso deve se despir ao máximo que lhe for possível (ainda que a plenitude seja intangível, buscá-la não o é) de pré-julgamentos e afins, bem como buscar, como verdadeiro detetive o contexto em que a matéria de sua análise ocorreu.

No caso da Epistemologia de Piaget, o cenário é a Europa, o Velho Continente, da Terra dos Pensadores (Alemanha), do Direito (Itália), do lluminismo (França) e tantas outras nações de gigantesco impacto na História Mundial. Quando pensamos na Inglaterra, a título de exemplo, basta que lembremos de Charles Robert Darwin (com homenagens à figura de Alfred 
Wallace) e sua Teoria da Evolução, a qual sacudira o dogmatismo, trazendo o Criacionismo ao debate.

Ainda na Inglaterra, Sir Isaac Newton, um dos maiores cientistas da História da Humanidade, já demonstrara a força do pensamento científico, racionalidade e da experimentação com suas descobertas sem precedentes. Não é sem razão que está esculpido na estátua de Newton, no Trinity College Cambridge: Qvi genvs Hvmanvm Ingenio Svperavit ("cuja genialidade ultrapassou o gênio humano"), ou ainda, nas palavras de Alexander Pope: "A Natureza e suas Leis estavam imersas em Trevas; Deus disse "Haja Newton", e tudo se iluminou".

Ainda nesta linha de conta, é de sabença global que a Europa contribuíra massivamente e fundamentalmente para o progresso das artes, das ciências, das tecnologias e, consequentemente, para o progresso da humanidade. No ardor das descobertas, houve correntes que defendiam que 0 conhecimento se pautava na razão e, de forma diametralmente oposta, houve quem advogasse pelo conhecimento como resultado da experiência; diz-se desta, Escola Empírica, daquela, Escola Racional.

O Método Positivista de Comte, as elucubrações de Descartes e Kant, o advento de novas descobertas em plúrimas áreas de estudo, dentre outros fatores, temperaram a Europa ao sabor do conhecimento, lauto banquete para Jean Piaget.

\section{CONSIDERAÇÕES FINAIS}

Conforme o presente trabalhou buscou explicitar, Jean Piaget muito contribuiu para o conhecimento científico e para a educação. Sua obra inaugurou uma metodologia de ensino, subversiva aos olhos dos mais conservadores e tradicionais professores e pedagogos pretéritos.

Ainda hoje, fortifica ao Psicólogo sua presença nas escolas, cuja participação se faz mister para promover a melhoria do ensino e das instituições de ensino, ventilando aos quatro cantos propostas psicopedagógicas. Piaget ainda usou do método científico para demonstrar suas hipóteses o que, per se, já robustece os laços do progresso científico. 
Premiado e homenageado em diversas localidades, sua teoria construtivista é de suma importância, especialmente para a Psicologia e Pedagogia, sendo referência em numerosas escolas e instituições de ensino nacionais e internacionais.

Finalmente, ressalta-se que a aplicação da Teoria em debate às Artes, sobretudo à Dança, deve-se ao fato de que esta se incorpora àquela no contemporâneo rol acadêmico das complementares, como é o caso também da música, da pintura, dos esportes.

Espera-se, em suma, que esta escrita sirva de estímulo para mais pesquisas específicas no tema dos entrelaces socioculturais e teóricos aqui apresentados, bem como que se possa contribuir para valorar a aplicação da Epistemologia Genética de Piaget em outros recônditos do saber humano. 


\section{REFERÊNCIAS}

ARAÚJO, C. R., CORREIA, M. F. B., LIMA, A. P. B. As Contribuições da Psicologia Cognitiva e a Atuação do Psicólogo no Contexto Escolar. Psicol. Reflex. Crit. Vol. 14, ㄲo 3. Porto Alegre, 2001. Acesso em: 22 de set. de 2020.

FALANDO SOBRE EPISTEMOLOGIA GENÉTICA. Disponível em: https://lumina.ufrgs.br/course/view.php?id=84. Acesso em 29/11/2020.

FERREIRO, Emilia. Atualidade de Jean Piaget. ArtMed: Porto Alegre, 2001.

GOMES, Luciano Carvalhais; BELLINI, Luzia Marta. Uma revisão sobre aspectos fundamentais da teoria de Piaget: possíveis implicações para o ensino de física. Rev. Bras. Ensino Fís. São Paulo, v. 31, n. 2, p. 2301.12301.10 (2009).

PIAGET, Jean. A equilibração das estruturas cognitivas. Rio de Janeiro: Zahar, 1975.

PIAGET, Jean. Seis Estudos de Psicologia. 25ํㅗㄹ ed. Rio de Janeiro: Forense Universitária, 2017.

SILVA, Gabriel Gomes de Souza; MACIEL, Cilene Maria Lima Antunes; FERNANDES, Cleonice Terezinha; FONTES, Tania Aparecida de Oliveira. As contribuições da dança (do ventre) no ensino-aprendizagem para crianças: uma óptica neurocientífica. Educação Pública, v. 20, no 4, 28 de janeiro de 2020. Disponível em: https://educacaopublica.cecierj.edu.br/artigos/20/4/ascontribuicoes-da-danca-do-ventre-no-ensino-aprendizagem-para-criancas-umaoptica-neurocientifica. Acesso em 05/12/2020.

TERRA, Marcia R. O Desenvolvimento Humano na Teoria de Piaget. UNICAMP: $\quad$ Campinas, $2005 . \quad$ Disponível em: http://www.unicamp.br/iel/site/alunos/publicacoes/textos/d00005.htm. Acesso em: 18 de out. 2020.

WADSWORTH, Barry. Inteligência e Afetividade da Criança. 4. Ed. São Paulo: Enio Matheus Guazzelli, 1996. 